Zulliger, R. et al. (2013). "She is my teacher and if it was not for her I would be dead": Exploration of rural South African community health workers' information, education and communication activities. AIDS Care: Psychological and Socio-medical Aspects of

\title{
"She is my teacher and if it was not for her I would be dead": Exploration of rural South African community health workers' information, education and communication activities
}

\author{
Rose Zulliger, Mosa Moshabela and Helen Schneider
}

\begin{abstract}
:
Community health workers (CHWs) are important resources in health systems affected by the HIV/AIDS pandemic. International guidelines on task-shifting recommend that CHWs can provide diverse HIV services, ranging from HIV prevention to counselling patients for lifelong antiretroviral therapy. There is, however, little evidence on the experiences with $\mathrm{CHW}$ delivery of these services in Africa. This qualitative study included 102 interviews that explored experiences with information, education and communication (IEC) activities provided by CHWs within rural South Africa. Semistructured interviews were conducted with CHWs $(n=17)$, their clients $(n=33)$ and the primary caregivers of these clients $(n=30)$, allowing for data source triangulation. Twenty-two follow-up interviews explored emergent themes from preliminary interviews. Despite limited formal education and training, $\mathrm{CHWs}$ in this study were significant providers of IEC, including provision of generic health talks and HIV-specific information and facilitation to support clients' entry and maintenance in the formal health system. They often incorporated local knowledge and understanding of illness in their communication. CHWs in this study were able to bridge the lifeworlds of the community and the formal services to expedite access and adherence to local clinics and other services. As mediators between the two worlds, CHWs reinterpreted health information to make it comprehensible in their communities. With growing formalisation of CHW programmes in South Africa and elsewhere, CHWs' important role in health service access, health promotion and health maintenance must be recognised and supported in order to maximise impact.
\end{abstract}

\section{Introduction}

In the many countries where lack of human resources is a critical barrier to the provision of HIV services (Barnighausen, Bloom, \& Humair, 2007), community health workers (CHWs) are an important resource (Lewin et al., 2010). CHWs' deployment has been a key mechanism for scaling up HIV service access (Schneider, Hlophe, \& van Rensburg, 2008). Guidelines on task-shifting have suggested that CHWs can provide diverse support activities, including identification and linkage of HIVpositive individuals to care, provision of basic HIV clinical services and counselling of patients for lifelong antiretroviral therapy (ART) (WHO, 2008). There is, however, little 
documentation of experiences with CHW delivery of these activities or of their impact within the African context.

CHWs are an important cadre in the provision of health services in South Africa. They gained prominence because of their potential to mitigate the effect of HIV/ AIDS on the health system (de Wet, 2012; Lewin et al., 2010) and to link the formal sector and communities (Lehmann \& Sanders, 2007). South Africa is now re-engineering its primary health care strategy to utilise CHWs in ward-based teams alongside professional nurses (Joint Primary Health Care Forum, 2012; National Department of Health, 2010; Pillay \& Barron, 2011). CHWs are expected to assess health needs, facilitate service access, provide community-based information, education and psychosocial support, deliver basic health care and support community campaigns. These tasks include the provision of information, education and communication (IEC). IEC is a group of activities that empower community members to initiate or maintain healthy behaviour and to develop social norms that support these behaviours (WHO, 2001). Yet, there is limited evidence on CHWs' IEC activities in Africa. In addition, CHWs official role in HIV-specific care is less defined in South Africa as the "20126 National Strategic Plan on HIV, Sexually Transmitted Infection and Tuberculosis" only described CHWs' involvement in HIV testing and postnatal follow-up (National Department of Health, 2012b). This study describes IEC activities provided by CHWs in a rural, South African sub-district to identify current capacities, practices and challenges.

\section{Study setting}

This study was conducted in the highly impoverished sub-district of Bushbuckridge, South Africa (National Department of Social Development, 2006). Bushbuckridge's 37 clinics and 3 hospitals provide services for a populace facing a quadruple burden of poverty, infectious disease, non-infectious disease and violence/injury. The HIV antenatal prevalence in the district was 35.8\% in 2011 (National Department of Health, 2012a). A large body of non-governmental organisations (NGOs) have developed in Bushbuckridge, the majority of which are home-based care (HBC) organisations (van Pletzen, Zulliger, Moshabela, \& Schneider, 2013).

\section{Methods}

This exploratory, descriptive study included 102 qualitative interviews with CHWs, their clients and the clients' primary caregivers. Interviews were conducted with the CHWclient-caregiver trio in order to provide multiple perspectives (Schneider \& Lehmann, 2010) and to improve the trustworthiness of findings through triangulation.

Semi-structured interviews were conducted between April and July 2010 with 17 CHWs from $9 \mathrm{HBC}$ organisations, 33 clients and 30 caregivers. Participants were purposively selected to maximise diversity of backgrounds and caregiver/illness experiences. Interview guides explored illness experience, caregiver roles and relationships, and perceptions of the quality of care provided. IEC activities were not specifically probed, but emerged as a prominent theme in interviews.

Follow-up interviews were conducted between August and October 2010 with seven CHWs, seven clients and eight caregivers. Trios were purposively selected for follow-up 
interviews to explore emergent themes, including IEC activities. Interviews also included clarity and probing questions based on primary interview findings. Ethical approval for the study was provided by the institutional research boards of the University of Cape Town, the University of Witwatersrand, the national Department of Social Development and the provincial Department of Health.

\section{Data analysis}

Interviews were translated and transcribed by a member of the team who conducted the interview. Transcripts were read by the primary author twice and then coded using Atlast.ti 6.2.16 (Scientific Software Development, 2010). Data were coded in a systematic manner using constant comparison to enhance understanding and facilitate source triangulation. Coding used an open, grounded approach, followed by focused coding of content related to the provision of information, preventive and promotive services, mediation within the home and facilitation of access to health services.

\section{Results}

Participants described diverse CHW services and experiences, yet there was a common narrative of the scope and nature of CHWs' activities. One CHW, his client and her caregiver trio are demonstrative of participants' experiences, as shown in Table 1. In this instance, the CHW, Abuti, had limited formal education, but received some training and developed his own techniques to perform IEC activities. His interaction with a patient (Tsakani) and her household included generic health talks, illness-specific support and caregiver capacity-building, playing a distinct role in this household's experience of HIV and pathways of care.

We describe the preparation of CHWs and their IEC role in more depth.

\section{Formal education and training}

CHWs described a range of educational and experiential backgrounds. While some CHWs entered CHW work with relevant skills, there were a number who had little formal education, as shown in Table 2. These CHWs were dependent on the predominantly tuberculosis (TB)- and HIV-related trainings offered by the HBC organisation, although 3 of the 17 interviewed reportedly received no training. Trained CHWs relayed information to peers who did not attend, cultivating a culture in which CHWs taught one another. CHWs valued the trainings, although one CHW mentioned difficulty in understanding training conducted in English.

\section{Locally developed IEC skills}

CHWs generally drew on existing skills or developed their own methods for educating clients, families and the community. Some CHWs presented their lessons in stages:

When I teach about TB today and teach about HIV tomorrow it's because I listened to his responses when I talked to him about $\mathrm{TB}$, and [these responses helped me] to understand that it will be a problem if I don't talk about HIV.

In addition to targeting messages based on perceived recipient needs, many CHWs, like Abuti (Table 1), emphasised the importance of repetition in knowledge transfer. 
CHWs incorporated local conceptions of illness and treatment into health talks and advice, including traditional medicine. One CHW explained his response to local beliefs in traditional illnesses:

Table 1. Representative community health worker (CHW), client and caregiver experiences with CHW's information, education and communication (IEC) activities.

\begin{tabular}{|c|c|}
\hline CHW competencies & Client experience \\
\hline $\begin{array}{l}\text { Abuti began volunteering at his local clinic in } 1990 \text {. Despite little } \\
\text { formal education, he gained substantial knowledge by attending } \\
\text { trainings and his work at the clinic. He drew upon this experience } \\
\text { when he started work with a local HBC organisation around } \\
2000 \text {. Abuti explained "I knew all these things before I joined the } \\
\text { organisation. I learnt them while I was still volunteering at the } \\
\text { clinic and also by reading many books and pamphlets". Abuti } \\
\text { also received additional training from his HBC organisation. } \\
\text { In the process of his work, Abuti adapts IEC messages to fit the } \\
\text { local context and has developed his own IEC techniques, } \\
\text { including repetition. He explained, "It's like a bible you have to } \\
\text { go preach that verse and even tomorrow go back to preach the } \\
\text { same verse. The person will eventually understand". }\end{array}$ & $\begin{array}{l}\text { Tsakani's husband and child became sick and the family spent a } \\
\text { lot of money on medications and traditional care. They both } \\
\text { passed away and then Tsakani herself became ill in } 2006 \text {. } \\
\text { She then met the CHW, Abuti, when he was going house-to- } \\
\text { house. Abuti explained that he encouraged her to go to the clinic, } \\
\text { but Tsakani mentioned that her own experience with her } \\
\text { husband's illness was also a strong motivation for her clinic } \\
\text { access. Tsakani went to the clinic and tested positive for HIV. She } \\
\text { took classes at the clinic, but she did not disclose her status to her } \\
\text { family. Tsakani was instructed by the clinic to bring a treatment } \\
\text { adherence supporter. She brought her granddaughter, Lindy, to } \\
\text { the clinic, but did not explain why. The doctor told Lindy that her } \\
\text { grandmother had HIV which was quite upsetting for Lindy. } \\
\text { Tsakani is now doing much better and adheres to her treatment. } \\
\text { Tsakani explained that Abuti checks on her and sometimes brings } \\
\text { her fruits. }\end{array}$ \\
\hline $\begin{array}{l}\text { IEC services } \\
\text { As a CHW, Abuti goes house-to-house giving generic health talks } \\
\text { and explaining about various illnesses. When he comes across a } \\
\text { sick person he will teach the ill person about their illness and } \\
\text { motivate clinic access. Abuti also teaches caregivers how to } \\
\text { provide care. }\end{array}$ & $\begin{array}{l}\text { Caregiver experience } \\
\text { Tsakani's granddaughter, Lindy, agreed that the CHW comes to } \\
\text { check on her grandmother, but she explained that she has little } \\
\text { interaction with him. }\end{array}$ \\
\hline
\end{tabular}

Most people were defaulting from treatment saying they are not suffering from TB but Tindzaka or Mafulara [illnesses with similar symptoms as TB, but attributed to witchcraft or sexual practices] with the result of that people were dying in large numbers. So we continue giving health talks to the very same people who were sick and most end up understanding that Tindzaka or Mafulara are more or less the same with TB.

CHWs also developed terminology which they perceived was more locally acceptable. The most frequent example of this was the euphemistic term "TB plus", used to describe clients who were perceived to be HIV positive without disclosing their status.

\section{CHW provision of IEC}

Despite limited training, CHWs were perceived by all respondents as significant providers of IEC. Care recipients valued CHWs' IEC services and tried to follow their advice. When asked about her relationship with the CHW, one client stated, "Our relationship is that she was my teacher and if it was not for her I would be dead by now, she is my best friend".

\section{Generic health talks}

Caregivers and clients frequently described CHWs as important health information resources within their communities. 


\begin{tabular}{lclr}
\hline CHW education & $N=16$ & CHW training & $N=17$ \\
\hline Primary school or less & $3(18.8)$ & Directly observed treatment, short-course for tuberculosis & $8(47.1)$ \\
Some secondary school & $4(25.0)$ & HIV/AIDS & $7(41.2)$ \\
Adult Basic Education \& Training & $3(18.8)$ & Voluntary counselling and testing for HIV & $6(35.3)$ \\
Grade 12 & $5(31.3)$ & Home-based care & $5(29.4)$ \\
Beyond grade 12 & $1(6.3)$ & First aid & $3(17.7)$ \\
& & Peer education & $2(11.8)$ \\
& & Ancillary health care & $1(5.9)$ \\
& None & $3(17.7)$ \\
\hline
\end{tabular}

CHWs gave generic health talks to reduce health risks and provision of "health talks" was mentioned by at least one member of 30 out of the 33 trios. These talks generally consisted of door-to-door visits within the community. Central, recurring messages were to: use condoms; keep your house clean; plant a garden; eat healthily; and get tested for HIV and for TB. These lessons were prompted by campaigns or were responsive to perceived family and community needs. For example, CHWs taught community members the importance of developing gardens in response to local food scarcity. Health talks, however, often were perceived as a conduit into households rather than as a focal service, possibly because CHW monitoring and evaluation (M\&E) systems generally did not account for these services. Health talks served as a non-threatening way to gain access to a family in order to find ill clients.

\section{Illness-specific health services}

Once clients were identified, CHWs supported them from initial symptoms, to clinic access through to cure, health stabilisation or dignified death. CHWs educated clients on their health condition, providing advice and guidance, along with support for selfcare. For example, CHWs frequently taught community members how to prepare oral rehydration solution (called "drips" locally), as described by a client, "[The CHWs] put drips on me and gave me treatment. They also told me what I should do if I feel it is going to happen again. Ever since then I am able to take care of myself”.

A central CHW service for clients was to motivate access or re-engagement with formal health services. Participants frequently described lost test results, frustrations and confusion within formal health services that affected their desire to return. In response, CHWs tried to explain the health system to clients. They also advocated on behalf of clients within the health services. For example, one CHW facilitated care reentry for a client who had turned to traditional medicine after not receiving his test results at the clinic. This $\mathrm{CHW}$ accompanied the client to the clinic and "explained [that] he is complaining that he has a long time submitted his sputum samples but he did not get any assistance. They then helped him".

CHWs also facilitated a "therapeutic alliance" between the community and the formal health services for those engaged in care. For example, CHWs helped to explain the clinic instructions when clients returned home confused or with English documents that they were unable to read. CHWs also taught the patients how to take their medical treatment and informed them about common side-effects. One client explained that she asked her CHW questions about her treatment: 
When I received the treatment for $\mathrm{TB}$, they [the CHWs] are the ones whom I was talking with to find out whether I can mix the treatments, or if I can take the TB treatment and leave the other treatment [ART].

Participants frequently expressed appreciation for CHWs' lessons, but there was evidence that some clients still confronted treatment adherence challenges.

\section{Caregiver capacity-building}

CHWs' services extended beyond the clients to also facilitate supportive caregiving. Many caregivers were concerned about the acquisition of HIV and, at times, stigmatised their care recipients. CHWs educated these families on HIV and TB and on patient care, as explained by one $\mathrm{CHW}$ :

We always meet this kind of the situation where by the whole family doesn't know how they can help someone who is sick, and so the CHW is able to help those kinds of families by teaching and bringing light to the family ... We were trained that the caregiver must learn not to give-up and how they must take care of patients and how to bathe them. After bathing them they sit down with them and support them by talking. That's what we then teach caregivers.

According to both CHWs and caregivers, some care-givers came to CHWs when they had questions and CHWs provided advice and support. Clients and care-givers were generally receptive of CHWs' advice, as one CHW explained, "He is accepting my advice and he also welcomes me when I give him some advice and he does what I tell him to do".

CHWs also enhanced caregivers' ability to protect their own health. For example, they stressed the need for open windows when someone had TB. Additionally, there was extensive evidence that CHWs promoted the use of gloves or plastic bags to cover hands when taking care of patients to prevent exposure to blood. One client explained that the $\mathrm{CHW}$ "taught us that if someone is not feeling well at home or having a running stomach we have to use hands gloves or plastic bags to touch that person to avoid blood contact". This client internalised this message and later said that "I was also advising [my caregiver] that she doesn't have to touch me without plastic bags on her hands". A different caregiver was, however, unhappy that she was instructed to use gloves by the CHW because she felt this was not respectful of her mother.

\section{Perceived challenges in provision of IEC}

The most significant challenge raised by CHWs was negotiating the place of traditional medicine in essaging:

[W]herever we are going we find people that are sick and when we arrive to teach we find that they already went to see the healer. They inform us that they didn't know anything, the only thing they knew about is that these kind of sicknesses can only be taken care of by healers and that the medical doctors can't treat it. So that's whereby I sit with that client and teach them that when they are sick he or she must go to the clinic and test in order to know what kind of sickness he/she might have. 
The client and caregiver of this CHW confirmed that they had tried traditional medicine because they did not know what else to do. CHWs explained to clients that they should go to the clinic, "We tell him that he must not be told otherwise because there is no traditional healer that is above a doctor, the hospital is the best; even TB is curable now" or, alternatively, that they should not mix treatments such as ART and traditional herbs. Some CHWs also communicated that traditional medicine could later be used if western medicine was ineffectual. A client explained:

[W]e were already thinking many things like the traditional healers but she [the CHW] said let's put aside the traditional healer stuff and we must start at the clinic and when the clinic fails we would consider the traditional healer.

Another challenge reported was that CHW's IEC activities were not always valued, particularly when the CHWs were young women discussing taboo subjects such as sex. This was particularly challenging in church-affiliated HBC organisations. One CHW explained, "the people in charge were pastors and the issues of condoms were never mentioned".

\section{Discussion}

Participants in this study described a range of IEC provided by CHWs. Despite limited education and training (Friedman, 2005), CHWs developed their own techniques to provide "generic health talks" and illness-specific support, encourage health service access and capacitate caregivers. Participants described the positive impact of CHW services, but many had negative experiences in the health services and some continued to rely on traditional care.

For health information to be effective it must be comprehensible, adequate and trustworthy (Thiede, 2005). CHWs' role, as members of the local community with access to both traditional and Western notions of illness, allowed them to provide effective HIV-related information. Rather than dismiss the existence of traditional illnesses - which would have been antithetical to local perceptions of ill health causation CHWs drew upon their local knowledge and were able to explain the relation of these illnesses to Western diseases and, in certain instances, acknowledge its place in care. By adapting messages to local realities, CHWs may make Western medicine more palatable to their community.

The CHWs in this study had low levels of training. This may, as elsewhere (Uys, 2002), increase distrust of CHWs by the formal health services. CHWs compensated for this lack of formal training through informal training and through the development of their own techniques. These included use of terminology and communication techniques that were more aligned with local understandings. By taking the time to adapt messages to local needs and more generally, to bridge lifeworlds, CHWs' IEC activities hold potential as key mechanisms for provision of information. It is important to note, however, that CHWs are not a homogenous group and some may derive more legitimacy from trainings than others (Swartz, 2013). Better training of CHWs is important, but it is essential that this training not undermine the natural adaption 
processes and instead should strengthen CHWs' biomedical skills and cultural competency.

Another important study finding was that general prevention "health talks" were not considered by many of the CHWs to be a central service. This was despite the fact that such health talks were a very common practice both in this study's setting, and in other parts of the country (Nxumalo, Goudge, \& Thomas, 2013). A key component in South Africa's reconsidered CHW model is the provision of community-based information, education and psychosocial support. The low priority placed on "generic health talks" and its exclusion from M\&E systems represents a missed opportunity for knowledge transfer. This study suggests that $\mathrm{CHWs}$ will require training and orientation on the importance of these services. It also highlights the need for improved documentation of CHWs' IEC services.

Finally, this study found that CHWs often helped to facilitate re-entry after clients had negative experiences in the formal health services. Similar findings have been noted in other South African research (Goudge, Gilson, Russell, Gumede, \& Mills, 2009). While not a solution to broader systemic challenges, this indicates that CHWs may hold potential as a mechanism to ameliorate or mitigate some challenges within the formal health system. This underscores CHWs' importance within continued discussions of the role of task-shifting to address shortages in human resources for health.

This study's inclusion of CHWs, clients and caregivers is novel in CHW literature. The study is, however, limited by its short duration. Participants may have also exaggerated CHWs' provision of IEC or their support for formal health services. The study also does not account for the diverse histories and missions of each of the included NGOs, which shape current CHW practices (van Rensburg, Wouters, \& de Wet, 2011). Additionally, the transferability of this study to other settings may be limited.

\section{Conclusion}

Through adaptation of messages and strong community understanding, CHWs in this study were important providers of IEC. It is, therefore, important that this role be protected. The work of CHWs is being formalised and integrated into the health system in South Africa and the risk exists that they may lose their foothold and identity in the community. It is imperative that CHWs continue to be drawn from the local community and that preventive and promotive work is supported. This will require adaptation of M\&E systems to value CHWs' IEC-related activities. CHW policy and practice must also ensure that CHWs have both the requisite biomedical skills and cultural competency to appropriately perform their work. It is only with adequate support that CHWs will be able to live up to their potential as teachers who save lives.

\section{Acknowledgements}

We would like to thank the study participants and local home-based care organisations for their participation in this research. This work would not have been possible without the RADAR research team and the Departments of Health and Social Development. Additionally, the following funders provided important support for this 
project: South Africa Netherlands Research Programme on Alternatives in Development (SANPAD) and AVERTing HIV and AIDS (AVERT). 


\section{References}

Barnighausen, T., Bloom, D. E., \& Humair, S. (2007). Human resources for treating HIV/AIDS: Needs, capacities, and gaps. AIDS Patient Care STDS, 21(11), 799-812. doi:10.1089/apc.2007.0193

de Wet, K. (2012). Redefining volunteerism: The rhetoric of community home-based care in (the not so new) South Africa. Community Development Journal, 47(1), 111-125. doi:10.1093/cdj/bsqo66

Friedman, I. (2005). Community health workers and community caregivers. In P. Ijumba \& A. Padarath (Eds.), South African health review (pp. 176-188). Durban: Health Systems Trust.

Goudge, J., Gilson, L., Russell, S., Gumede, T., \& Mills, A. (2009). Affordability, availability and acceptability barriers to health care for the chronically ill: Longitudinal case studies from South Africa. BMC Health Services Research, 9, 75. doi:10.1186/1472-6963-9-75

Joint Primary Health Care Forum. (Producer). (2012). Re-engineering Primary Health Care for South Africa- Ward Based Primary Health Care Outreach Teams. Retrieved from jphcf.org.za/sites/../PHC\%2oReengineer\%206\%20july\%202012_o.pdf

Lehmann, U., \& Sanders, D. (2007). Community health workers: What do we know about them? The state of the evidence on programmes, activities, costs and impact on health out- comes of using community health workers. Geneva: World Health Organization.

Lewin, S., Munabi-Babigumira, S., Glenton, C., Daniels, K., Bosch-Capblanch, X., van Wyk, B. E., ... Scheel, I. B. (2010). Lay health workers in primary and community health care for maternal and child health and the manage- ment of infectious diseases. Cochrane Database of Systematic Reviews, 3, CDoo4015. doi:10.1002/14651858. CD004015.pub3

National Department of Health. (2010). Re-engineering Prim-ary Health Care in South Africa. Discussion Document. Pretoria, South Africa.

National Department of Health. (2012a). The 2011 National Antenatal Sentinel HIV \& Syphilis Prevalence Survey in South Africa. Pretoria, South Africa. Retrieved from http://www.doh.gov.za/docs/presentations/2013/Antenatal_Sentinel_survey_Report2012_final.pdf

National Department of Health. (2012b). National Strategic Plan on HIV, STIs and TB: 2012-2016. Pretoria, South Africa. Retrieved from http://www.doh.gov.za/docs/strat- docs/2012/NSPfull.pdf

National Department of Social Development. (2006). Depart- ment of Social Development nodal baseline survey: Bushbuckridge results. Retrieved from www.sarpn.org.za/.../Bushbuckridge_DSD_nodal_baseline_report.pps

Nxumalo, N., Goudge, J., \& Thomas, L. (2013). Outreach services to improve access to health care in South Africa: Lessons from three community health worker programmes. Global Health Action, 6, 219-226. doi:10.3402/gha.v6io.19283

Pillay, Y., \& Barron, P. (2011). The implementation of PHC re- engineering in South Africa. Retrieved from http://www.phasa.org.za/the-implementation-of-phc-reengineering-in-south-africa/ 
Schneider, H., Hlophe, H., \& van Rensburg, D. (2008). Community health workers and the response to HIV/ AIDS in South Africa: Tensions and prospects. Health Policy and Planning, 23(3), 179-187. doi:10.1093/heapol/cznoo6

Schneider, H., \& Lehmann, U. (2010). Lay health workers and HIV programmes: Implications for health systems. AIDS Care, 22(Suppl. 1), 60-67. doi:10.1080/09540120903483042

Scientific Software Development. (2010). Atlas.ti for Windows, Rel. 6.2. Berlin, Germany: Author.

Swartz, A. (2013). Legacy, legitimacy, and possibility: An exploration of community health worker experience across the generations in Khayelitsha, South Africa. Medical Anthropology Quarterly, 27(2): 139-154. doi:10.1111/maq.12020

Thiede, M. (2005). Information and access to health care: Is there a role for trust? Social Science and Medicine, 61(7), 1452-1462. doi:10.1016/j.socscimed.2004.11.076

Uys, L. R. (2002). The practice of community caregivers in a home-based HIV/AIDS project in South Africa. Journal of Clinical Nursing, 11(1), 99-108. doi:10.1046/j.1365-2702.2002.00566.x

van Pletzen, E., Zulliger, R., Moshabela, M., \& Schneider, H. (2013). The size, characteristics and partnership networks of the health-related non-profit sector in three regions of South Africa: Implications of changing primary health care policy for community-based care. Health Policy and Planning. doi:10.1093/heapol/czto58

van Rensburg, D. J., Wouters, E., de Wet, K. (2011). The evolving socio-political context of community health worker programmes in South Africa: Implications for historical analysis. A commentary on van Ginneken, Lewin and Berridge "the emergence of community health worker programmes in the late-apartheid era in South Africa: An historical analysis" (2010). Social Science and Medicine, 72, 1021-1024. doi:10.1016/j.socscimed.2011.01.026

WHO. (2001). Information, education and communication: Lessons from the past; perspectives for the future. Depart- ment of Reproductive Health and Research. Occasional Paper 6. Retrieved from http://www.who.int/entity/repro ductivehealth/publications/health_systems/WHO_RHR_01_22/en/index.html.

WHO. (2008). Task shifting: Rational redistribution of tasks among health workforce teams: Global recommendations and guidelines. Retrieved from http://www.who.int/healthsystems/TTR-TaskShifting.pdf 